\title{
Removal of pharmaceuticals in conventionally treated wastewater by a polishing Moving Bed Biofilm Reactor (MBBR) with intermittent feeding
}

Tang, Kai; Ooi, Gordon Tze Hoong; Litty, Klaus; Sundmark, Kim; Kaarsholm, Kamilla Marie Speht; Sund, Christina ; Christenson, Magnus; Bester, Kai; Andersen, Henrik Rasmus

Published in:

Bioresource Technology

Link to article, DOI:

10.1016/j.biortech.2017.03.159

Publication date:

2017

Document Version

Peer reviewed version

Link back to DTU Orbit

Citation (APA):

Tang, K., Ooi, G. T. H., Litty, K., Sundmark, K., Kaarsholm, K. M. S., Sund, C., Christenson, M., Bester, K., \& Andersen, H. R. (2017). Removal of pharmaceuticals in conventionally treated wastewater by a polishing Moving Bed Biofilm Reactor (MBBR) with intermittent feeding. Bioresource Technology, 236, 77-86.

https://doi.org/10.1016/j.biortech.2017.03.159

\section{General rights}

Copyright and moral rights for the publications made accessible in the public portal are retained by the authors and/or other copyright owners and it is a condition of accessing publications that users recognise and abide by the legal requirements associated with these rights.

- Users may download and print one copy of any publication from the public portal for the purpose of private study or research.

- You may not further distribute the material or use it for any profit-making activity or commercial gain

- You may freely distribute the URL identifying the publication in the public portal 


\section{Removal of pharmaceuticals in conventionally treated wastewater by a polishing Moving Bed Biofilm Reactor (MBBR) with intermittent feeding}

Kai Tang ${ }^{1}$, Gordon T.H. Ooi ${ }^{1,2}$, Klaus Litty ${ }^{3}$, Kim Sundmark ${ }^{4}$, Kamilla M. S. Kaarsholm ${ }^{1}$, Christina Sund ${ }^{4}$, Caroline Kragelund ${ }^{3}$, Magnus Christenson $^{5}$, Kai Bester ${ }^{2}$, Henrik R. Andersen ${ }^{1 *}$

${ }^{1)}$ Department of Environmental Engineering, Technical University of Denmark, Miljøvej 113, 2800 Kgs. Lyngby, Denmark

${ }^{2)}$ Environmental Science, Århus University, Frederiksborgsvej 399, 4000 Roskilde, Denmark

${ }^{3)}$ Department of Chemistry and Biotechnology, Danish Technological Institute, Kongsvang Allé 29, DK-8000 Århus C, Denmark

4) Veolia Water Technologies, Haslegårdsvæenger 18, 8210 Århus V, Denmark

5) Veolia Water Technologies - AnoxKaldnes, Klosterängsvägen 11A, Se-226 47 Lund, Sweden

*Corresponding author: henrik@ndersen.net

\section{Highlights}

- Biofilm, intermittently fed with wastewater, was used to polish WWTP effluent

- Biofilms were able to significantly remove ammonia for over $95 \%$

- Biofilm degraded pharmaceuticals not degraded by activated sludge in the WWTP

- Diclofenac and atenolol were removed at $>50 \%$ from WWTP effluent by the polishing biofilm

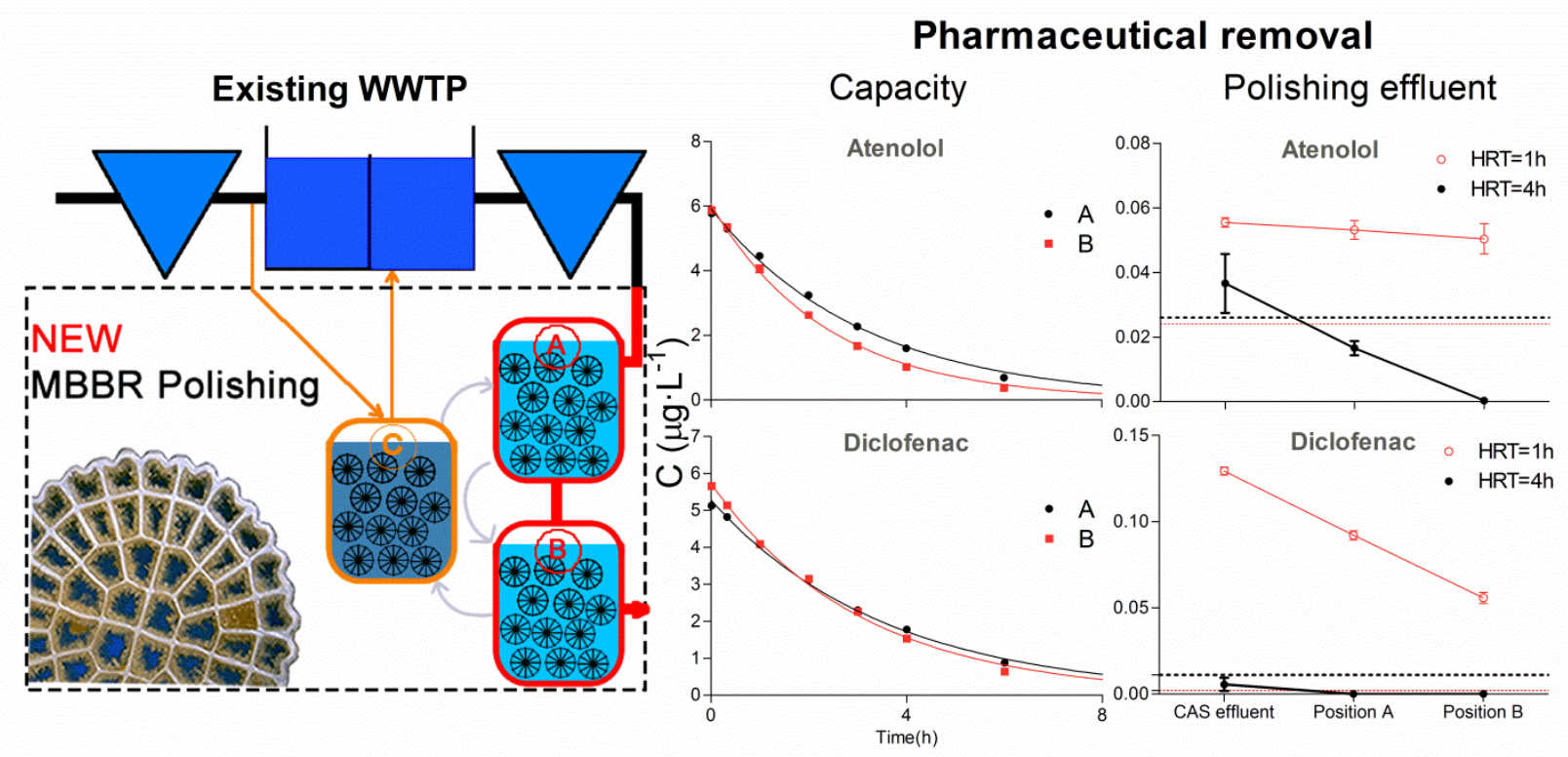

Abstract Previous studies have demonstrated that aerobic moving bed biofilm reactors (MBBRs) remove pharmaceuticals better than activated sludge. Thus we used a MBBR system to polish the effluent of an activated sludge wastewater treatment plant. To overcome that effluent contain insufficient organic matter to sustain enough biomass, the biofilm was intermittently fed with raw wastewater.

The capacity of pharmaceutical degradation was investigated by spiking pharmaceuticals. Actual removal during treatment was assessed by sampling the inlets and outlets of reactors. The removal of the majority of pharmaceuticals was enhanced through the intermittent feeding of the MBBR. First-order rate constants for pharmaceutical removal, normalised to biomass, were significantly higher compared to other studies on activated sludge and suspended biofilms, especially for diclofenac, metoprolol and atenolol. Due to the intermittently feeding, degradation of diclofenac occurred with a half-life of only 2.1 hours and was thus much faster than any hitherto described wastewater bioreactor treatment.

Key Words: Pharmaceuticals; Suspended biofilm; End-of-pipe; Diclofenac; Degradation. 


\section{Introduction}

The widespread detection of pharmaceuticals in terrestrial and aquatic systems has fuelled concerns on ecosystem health (Zuccato et al., 2010). As pharmaceuticals are designed especially to be bioactive in low concentrations there are potential risks to humans via the consumption of food and water containing pharmaceutical residues (Santos et al., 2009).

Pharmaceuticals and their metabolites are excreted through urine and faeces after human consumption. Additionally, uncontrolled and illegal drug disposal can contribute to the load of pharmaceuticals in wastewater (Bottoni et al., 2010; Emke et al., 2014; Muñoz et al., 2010). Traditional wastewater treatment processes (based on conventional activated sludge, CAS) are generally only able to remove a small fraction of the incoming pharmaceuticals (Verlicchi et al., 2012a, 2012b).

So far, solutions concerning pharmaceuticals entering the environment through treated wastewater have involved the physical-chemical polishing of CAS WWTP effluents. Activated carbon has been demonstrated to have high capacity to adsorb pharmaceuticals when used in post-treatment/polishing steps for CAS treatment (Rivera-Utrilla et al., 2009; Simazaki et al., 2008). Ozonation is currently the typical process to remove organic micropollutants (Hollender et al., 2009) from wastewater. However, compared with biological treatment processes, both activated carbon and ozone increase energy consumption and maintenance cost related to wastewater treatment. During the last few years, investigations on using biofilm reactors to remove micro-pollutants have started. The moving bed biofilm reactors (MBBRs) were developed in the late 1980s and early 1990s in Norway and Sweden (Hem et al., 1994) for enhanced BOD and nitrogen management (nitrification and denitrification) in compact reactors (Biswas et al., 2014; Oliveira, 2014). MBBRs consist of tanks filled with submerged low-density (slightly less than $1.0 \mathrm{~g} \cdot \mathrm{cm}^{-3}$ ) plastic (polypropylene) carriers covered by biofilms. A discussion to use this approach for removal of micropollutants has recently started(Chen et al., 2008; Falås et al., 2016, 2012; Luo et al., 2015; Tang et al., 2017).

Falås et al. (2012) found that there were distinct differences in removal efficiencies of pharmaceuticals by activated sludge and suspended biofilm carriers: the higher degradation rates per unit of biomass were achieved with the biofilm reactor compared to activated sludge. Additionally, diclofenac was clearly but slowly degraded by the biofilm, while activated sludge was unable to degrade this compound. MBBRs have been demonstrated to have considerably higher removal rates for selected pharmaceuticals than the activated sludge process and membrane bioreactors (Vieno and Sillanpää, 2014; Zupanc et al., 2013). Moreover, Escolà Casas et al. (Escolà Casas et al., 2015a) indicated 21 out of 26 pharmaceuticals could be degraded more than $20 \%$ by a three-stage MBBR. In these experiments, the first stage fed by raw wastewater had the highest amount of biomass, while the last stage, fed by the effluent of the second stage, had the least biomass. This resulted for most compounds in high removal of pharmaceuticals in the first stage compared to the other stages. However, the specific activity of the biomass towards the micro-pollutants was in contrast to that: the highest turnover per gram biomass was found in the last stage and the least turnover per gram biomass was found in the first stage. Similar findings were published for a hybrid system (combination of MBBR and activated sludge): for $50 \%$ of investigated pharmaceuticals, the highest activity per gram biomass was found for the last stage (Escolà Casas et al., 2015b). Mazioti et al. $(2016,2015)$ found similar effects in staged and hybrid systems for removal of benzotriazoles and stressed the effect of staging the biofilm reactors as biodegradation activity for some compounds only occurred after the first stage of reactors. Probably, the carbon supply is critical for the removal of pharmaceuticals.

In this study we aimed to evaluate whether MBBRs could be used to polish pharmaceuticals from effluents of a CAS WWTP with the intention to provoke growth of biomass that is able to degrade pharmaceuticals. To overcome problems with biomass generation due to too low substrate concentrations we applied for the first-time intermittent feeding of the biofilm in the MBBR reactors. We used raw wastewater taken after primary clarification (settled raw wastewater) as an intermittent feed for boosting biomass while the biofilms were usually operated with effluent. The ability of biofilms to remove pharmaceuticals was studied by batch experiments and by continuous influent-effluent sampling. 


\section{Materials and methods}

\subsection{Configuration of MBBR system}

The experiments were conducted with effluent water from Viby WWTP in Aarhus, Denmark. The WWTP treats municipal wastewater and has a capacity of 83,000 Population Equivalent. The treatment consists of CAS treatment with BOD removal as well as nitrification and denitrification. The effluent used for this experiment was taken between the CAS reactor and the polishing sand filters. It contained in average 8.1 $\mathrm{mg} \cdot \mathrm{L}^{-1} \mathrm{TOC}, 1.0 \mathrm{mg} \cdot \mathrm{L}^{-1} \mathrm{NH}_{4}^{+}-\mathrm{N}$, and $7.4 \mathrm{mg} \cdot \mathrm{L}^{-1} \mathrm{NO}_{3}{ }^{-}-\mathrm{N}$.

This experiment included three identical glass reactors of $3 \mathrm{~L}$ each containing 500 Anoxkaldnes ${ }^{\mathrm{TM}} \mathrm{K} 5$ carriers (AnoxKaldnes, Lund, Sweden), which resulted in a filling ratio of $50 \%$. Each reactor was aerated with atmospheric air with a flow rate of $300 \mathrm{~L} \cdot h^{-1}$ to have sufficient oxygen level and to mix the carrier. A two-staged MBBR treatment train (reactor 1 and 2 in position A and B; Fig. 1(a)) was fed with CAS effluent and performed as polishing reactors. Another MBBR treatment train with a single reactor (reactor 3 in position C) was fed with settled raw wastewater, which was used to enhance biofilm growth on the carriers (regeneration). After two days of operation, the feeding of reactors in these two MBBR treatment trains was changed, so the regenerated reactor (reactor 3) was placed in position A in the flow scheme and reactor 1 in position B, and thus reactor 2 was regenerated (Fig. 1(b)). Then, after running for another two days, the feeding to reactors in current two MBBR treatment trains was changed again as mentioned above. This was followed by another three days of operation before changing the next feeding so that the reactors reverted to their initial position in the flow scheme (Fig. 1(a)). This change of feeding scheme was conducted three times per week (see Fig. S1 of supplementary information (SI) for an alternative presentation of the change of feeding).

The system's biofilms were grown and incubated for four months before conducting the experiments. In this period the flow was $6 \mathrm{~L} \cdot \mathrm{h}^{-1}$, which resulted in a hydraulic retention time (HRT) of $0.5 \mathrm{~h}$ in each reactor and $1 \mathrm{~h}$ for the entire two-stage MBBR treatment train. For regeneration one-tenth the flow of the polishing mode was used, giving a hydraulic retention time of $5 \mathrm{~h}$ in the reactor in position $\mathrm{C}$.

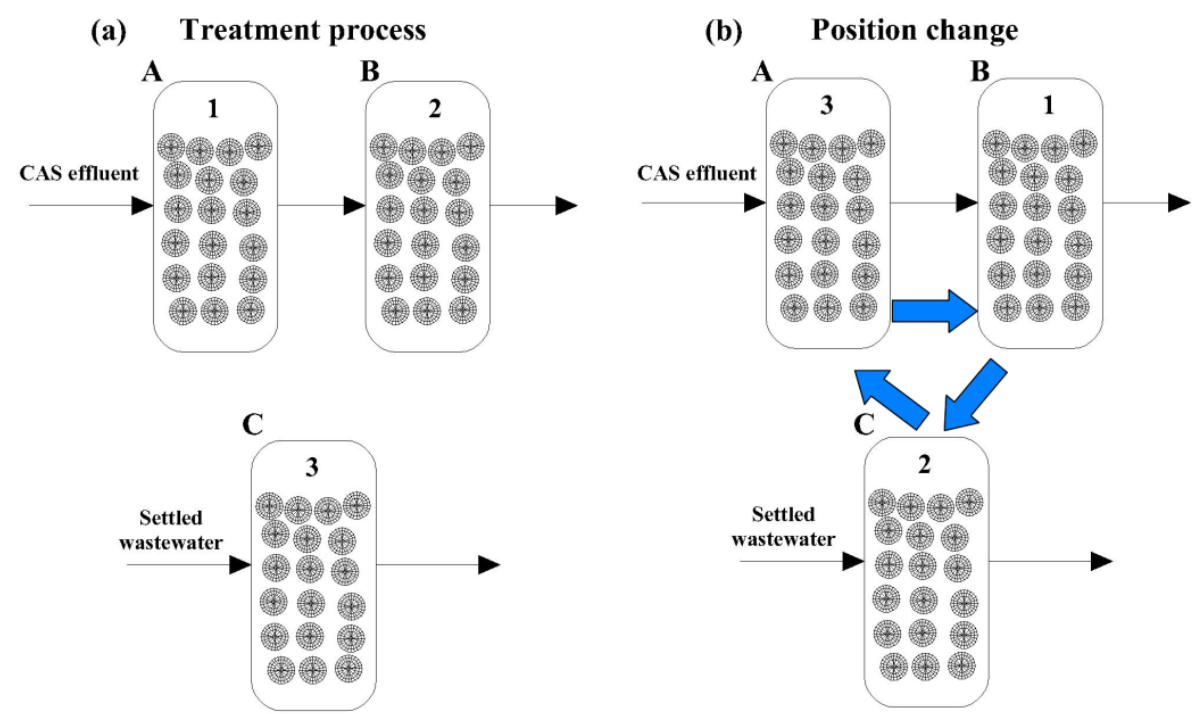

Fig. 1. Configuration of MBBR system: (a) Operation of a two-stage MBBR treatment train polishing effluent water from the Viby WWTP (positions A and B), while the growth of biofilm was stimulated in another MBBR treatment train with single reactor (position C). (b) Every Monday, Wednesday and Friday the positions of the reactors were changed to move the feeding to another reactor. The last reactor from the CAS effluent treatment line (position B) was moved to be fed with settled raw wastewater (position $\mathrm{C}$ ) while the reactor that was just fed was allocated as the first polishing reactor (position $\mathrm{A}$ ) and thus the reactor in position A moved to position $B$.

\subsection{MBBR system and experiments}

\subsubsection{Characterisation of MBBR performance}

Common wastewater parameters for the operation of the MBBRs were measured with standard methods over the entire period (four months), in which the experimental polishing system operated (Table 1). To test the influence of interchanged feeding on the two-stage MBBR treatment train performance (Fig. 3), dissolved organic carbon (DOC) and $\mathrm{NH}_{4}{ }^{+}-\mathrm{N}$ removal were studied over two days between two changes of feeding to 
reactors in the two-stage MBBR treatment train. Samples were taken from the WWTP's effluent (influent into the reactor in position A) and the reactor in positions A and B at initial time (t=0), t=8, 24, 32 and $48 \mathrm{~h}$. Similarly, the stability of the effluent from the two-stage MBBR train was investigated by analysing two parameters (DOC and $\mathrm{NH}_{4}{ }^{+}-\mathrm{N}$ ) at the same time every day of an entire cycle of changes of reactor positions in the MBBR treatment train mentioned above (seven days).

\subsubsection{Capacity for the degradation of pharmaceuticals (batch experiment)}

To evaluate the potential capacity for pharmaceutical degradation by each reactor, the flow was stopped by shutting down all pumps and interrupting all flow paths, as described in Fig. 2(a). To ensure that all compounds were present a mix of 33 compounds was added to each reactor, which resulted in compoundspecific starting concentrations between $3 \mu \mathrm{g} \cdot \mathrm{L}^{-1}$ and $20 \mu \mathrm{g} \cdot \mathrm{L}^{-1}$. The mix of all compounds was dissolved in $500 \mu \mathrm{l}$ of methanol, which added $200 \mathrm{mg} / \mathrm{L}$ chemical oxygen demand (COD) to each reactor. Compared with typical medium strength raw wastewater contains $300 \mathrm{mg} / \mathrm{L}$ COD (Henze et al., 2008) and knowing that methanol degrades very fast by wastewater bacteria the effect on the biomass was considered to be minor. This could be further explained by that the methanol could potentially produce up to $80 \mathrm{mg}$ biomass per litre from the methanol which compares to that each reactor contains already more than $1 \mathrm{~g} / \mathrm{L}$ biomass in the biofilm. After spiking, $10 \mathrm{~mL}$ samples were taken from each reactor using a glass pipette at $1 \mathrm{~min}, 20 \mathrm{~min}, 1$ h, 2 h, 3 h, 4 h, 6 h, 10.5 h, 21.5 h, 24 h and 25.5 h.

\subsubsection{Removal of pharmaceuticals during treatment (continuous flow experiment)}

The actual removal of pharmaceuticals in the MBBR system was investigated by continuous influent-effluent sampling in two experiments: total HRT in the two reactors was $1 \mathrm{~h}$ (four months operation before sampling) in the first experiment and $4 \mathrm{~h}$ in the second (one week operation before sampling). No pharmaceuticals were added in this experiment, and only the two-stage MBBR treatment train operating on the WWTP's effluent were investigated (see Fig. 2(b)). The principle behind the sampling was to follow the hydraulic retention time, thus, sampling for reactor A's effluent was conducted at one reactor's HRT ( 0.5 or $2 \mathrm{~h}$ ) and sampling for reactor B's effluent was conducted at an entire two-stage MBBR treatment train's HRT (1 or 4 h). For instance, sampling of inlet to reactor A equalled to $t=0$, then, sampling of reactor A's effluent equalled to $\mathrm{t}=0.5$ or $2 \mathrm{~h}$, at the end, sampling for reactor B's effluent equalled to $\mathrm{t}=1$ or $4 \mathrm{~h}$. 
(a) Batch experiment

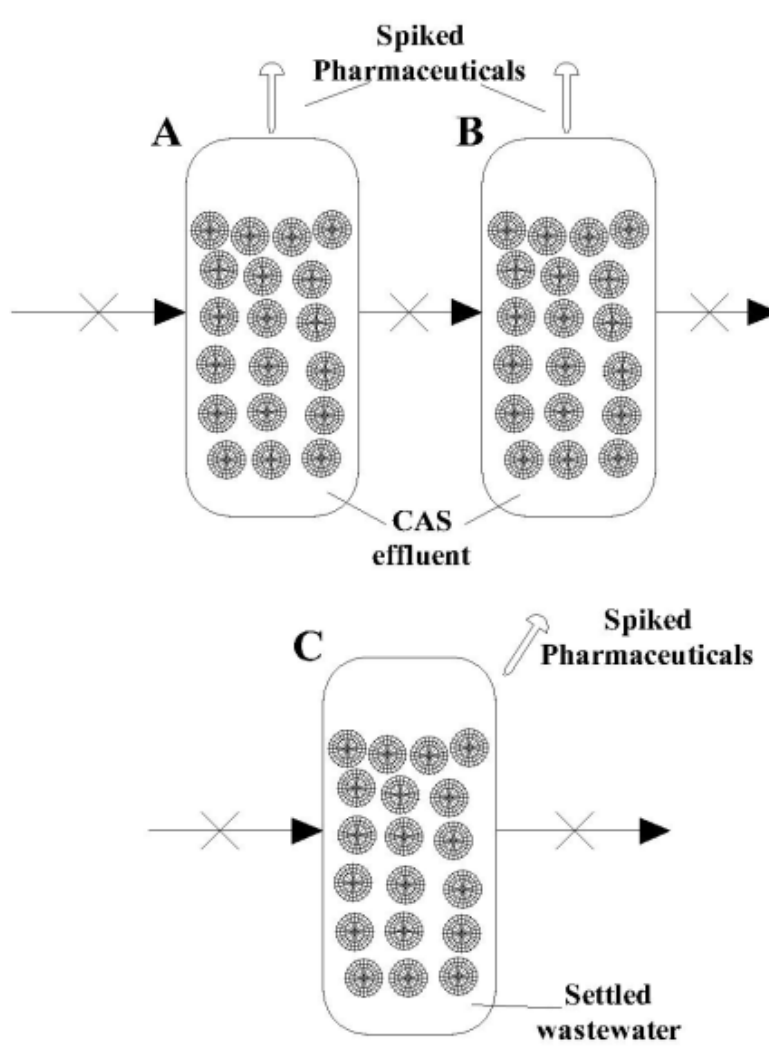

(b) Sampling for continuous flow experiment

Fig. 2. Configuration of the staged MBBR during the batch and continuous flow experiments: (a) the batch experiments were carried out to measure the biofilms' capacity to degrade pharmaceuticals and the flow was discontinued while concentrations of spiked pharmaceuticals were measured with time. (b) During the continuous flow experiment.

\subsection{Chemicals}

The compounds used for calibration as well as for spiking in the batch experiment were obtained from different suppliers, as presented in the supplementary information (Tables S1 and S2). The compounds analysed in this study are as follows:

Antibiotics: ciprofloxacin, sulfadiazine, sulfamethizole, sulfamethoxazole, trimethoprim, azithromycin and the sulfadiazine metabolite acetyl-sulfadiazine. Blood pressure regulators: atenolol, metoprolol, propranolol and sotalol. Analgesics: carbamazepine, diclofenac, ibuprofen, phenazone and tramadol. Antidepressants: venlafaxine. X-ray contrast media: iopromide, iohexol and iopamidol.

\subsection{Quantification of pharmaceuticals}

\subsubsection{Sample preparation}

In both experiments, $10 \mathrm{~mL}$ of sample were transferred into a glass vial which contained $3 \mathrm{~mL}$ of methanol, following which it was stored in the fridge at $4^{\circ} \mathrm{C}$. After all the experiments were completed, the samples were transported to the laboratory in cool conditions (ice boxes). Once in the laboratory, the samples were stored at $-20^{\circ} \mathrm{C}$. For analysis, the samples were taken from the freezer and left to reach room temperature, before $1.5 \mathrm{~mL}$ of each sample was transferred into an HPLC vial. Successively, each sample was centrifuged at $6000 \mathrm{rpm}$ for $10 \mathrm{~min}$, and $900 \mu \mathrm{L}$ of the supernatant was transferred to a new HPLC vial by a syringe. A total of $100 \mu \mathrm{L}$ internal standard solution (sulfadiazine ${ }^{13} \mathrm{C}_{6}$; trimethoprim $\mathrm{D}_{3}$; acetyl-sulfadiazine ${ }^{13} \mathrm{C}_{6}$; ciprofloxacin $\mathrm{D}_{8}$; clindamycin $\mathrm{D}_{3}$; citalopram $\mathrm{D}_{6}$; propanolol $\mathrm{D}_{7}$; $\left({ }^{13} \mathrm{C}, \mathrm{D}_{3} \mathrm{~N}\right.$-methyl)- erythromycin; ibuprofen $\mathrm{D}_{3}$ ) was added to each sample, using a glass syringe. Finally, these samples were analysed by using HPLC-MS/MS, and $100 \mu \mathrm{L}$ of injection for both the batch and the continuous experiment were applied. 


\subsubsection{Pharmaceutical analysis (HPLC-MS/MS)}

HPLC-MS/MS was used for quantifying pharmaceuticals in the effluent of the WWTP and the MBBR reactors. The HPLC was equipped with dual low-pressure mixing ternary gradient system Ultimate 3000 from Dionex. This system consisted of a pump, a column oven and a degasser, all of which were 3000 series, and a 3000 TSL auto-sampler (WPS 3000 TSL). The HPLC was operated with two ten-port Valco valves. The mass spectrometer was an API 4000 (ABSciex, Framingham, MA, USA). Details on the HPLC and MS/MS are documented in Escolà Casas et al. (2015a), while the limit of quantifications (LOQs) are shown in Table S3 of the Supplementary Information. LOQs are derived from the lower of two multiple reaction monitoring (MRM) signals. In cases that concentrations are presented below LOQ, the quantification was only performed with the MRM giving the better signal.

\subsection{Biomass concentration determination of carriers}

Detailed procedures regarding of biomass concentration measurement are documented in Escolà Casas et al. (2015a). Briefly, carriers from each reactor were placed in an aluminium-foil cup, dried overnight at $105{ }^{\circ} \mathrm{C}$, and weighed. The carriers were then cleaned and washed. After cleaning the carriers were again dried at $105^{\circ} \mathrm{C}$ overnight. The biomass content on the carriers was now calculated as the difference in weight before and after cleaning of carriers.

\subsection{Data treatment}

\subsubsection{Batch experiment}

Concentrations of each compound were fitted with single first-order degradation kinetics (Equation 1), using Graphpad Prism 5.0. To evaluate the results, the rate constant and correlation coefficient $\left(R^{2}\right)$ from fitting curves for each compound in different reactors were compared.

$$
C=C_{0} \cdot e^{-k t}
$$

\subsubsection{Continuous flow experiment}

Removal efficiency was calculated by comparing concentrations between influent wastewater and the effluent of reactors A and B.

Removal $=1-\frac{\text { Concentration of effluent in each reactor }}{\text { Concentration of influent }}$

\subsubsection{Predicted removal based on batch experiments}

To calculate and predict removal from the batch experiments, equation (3) was used

$$
\text { Removal }=1-\frac{1}{\left(1+k_{A} H R T_{A}\right)\left(1+k_{B} H R T_{B}\right)}
$$

Where $\boldsymbol{k}$ symbolises the reaction rate constants (as obtained from equation (1)) of each reactor (A and B) and HRT is the hydraulic retention time.

\section{Results and discussion}

\subsection{Performance of intermittently fed MBBRs on wastewater parameters}

Common wastewater parameters were measured to characterise the stability and function of the polishing reactors in the two-stage MBBR treatment train.

\subsubsection{Operations of intermittent fed system}

In Table 1, CAS effluent represents effluents from the full-scale WWTP and wastewater taken after the primary settler (settled raw wastewater) was used for feeding the reactor in position C. The flow to the three reactors was changed, as mentioned in section 2.1. When comparing the differences of concentrations of $\mathrm{NH}_{4}{ }^{+}-\mathrm{N}$ between influent and the reactors in positions $\mathrm{A}$ and $\mathrm{B}$, this MBBR system demonstrated good ability to nitrify, which accorded with aerobic conditions as dissolved oxygen concentration (DO) in each reactor was above $2 \mathrm{mg} \cdot \mathrm{L}^{-1}$. The average biomass in position A, B and C during the period 13/04/15 to 24/08/2015 are: $1.3 \pm 0.2,1.1 \pm 0.2$ and $1.0 \pm 0.2 \mathrm{~g} \cdot \mathrm{L}^{-1}$, respectively. Therefore, biomass was considered be identical in all three reactors which agrees to the fact that there is not enough time in position A and B to lose significant amounts of biomass. However, the biomass data used to calculate biomass related reaction rate constants $\left(\mathrm{k}_{\mathrm{bio}}\right)$ (3.1.2) were measured at the same day as the concentrations of micropollutants (batch 
experiments). Thus, the biomass used for calculating $\mathrm{k}_{\mathrm{bio}}$ in position A, B and C was 1.2, 1.5 and $1.4 \mathrm{~g} \cdot \mathrm{L}^{-1}$ respectively, rather than the long term average value.

Table 1. Common parameters of reactors in three positions in MBBRs over a long time period (13/04/2015-24/08/2015). Indicated intervals $( \pm)$ are standard deviation of means. DO: Dissolved oxygen, DOC: dissolved organic carbon.

\begin{tabular}{cccccc}
\hline Reactor & $\begin{array}{c}\mathrm{HRT} \\
(\mathrm{h})\end{array}$ & $\mathrm{pH}$ & $\begin{array}{c}\mathrm{DO} \\
\left(\mathrm{mg} \cdot \mathrm{L}^{-1}\right)\end{array}$ & $\begin{array}{c}\mathrm{DOC} \\
\left(\mathrm{mg} \cdot \mathrm{L}^{-1}\right)\end{array}$ & $\begin{array}{c}\mathrm{NH}_{4}{ }^{+}-\mathrm{N} \\
\left(\mathrm{mg} \cdot \mathrm{L}^{-1}\right)\end{array}$ \\
\hline CAS effluent & & $7.4 \pm 0.1$ & & $8.2 \pm 1.3$ & $0.84 \pm 0.44$ \\
Position A & 0.5 & $7.7 \pm 0.5$ & $7.2 \pm 0.9$ & $8.1 \pm 1.2$ & $0.16 \pm 0.10$ \\
Position B & 0.5 & $8.0 \pm 0.5$ & $8.3 \pm 0.9$ & $8.7 \pm 2.1$ & $0.04 \pm 0.04$ \\
Settled raw wastewater & & $7.6 \pm 0.1$ & & $22 \pm 5.0$ & $24 \pm 5$ \\
Position C & & $7.8 \pm 0.5$ & $7.4 \pm 1.4$ & $9.1 \pm 1.6$ & $0.28 \pm 0.16$ \\
\hline
\end{tabular}

\subsubsection{Influence of interchange feeding to a two-stage MBBR treatment train}

DOC and ammonium removal in a two-stage MBBR treatment train with interchange feeding is shown in Fig. 3(a-d). $\mathrm{NH}_{4}{ }^{+}-\mathrm{N}$ removal in position A and across the entire system was $89 \%$ and $99 \%$, respectively. The removal of both DOC and $\mathrm{NH}_{4}{ }^{+}-\mathrm{N}$ was very stable for the reactors in the two-stage MBBR treatment train (Figs. 3 (c; d)) in between two interchanges of feeding to reactors. The concentrations of DOC and ammonia in the effluent of the two-stage MBBR treatment train were measured each day during an entire change of feeding to the reactors (Figs. S2 (e, f)). A small variation in effluent of the two-stage MBBR train was observed, but the average value was in accordance with the measured values in position B in Figs. 3 (a, b). Furthermore, it can be seen that the entire change of feeding to reactors in the two-stage MBBR treatment train did not affect the removal of DOC and $\mathrm{NH}_{4}{ }^{+}-\mathrm{N}$, and thus we can conclude that the system was stable.

(a)
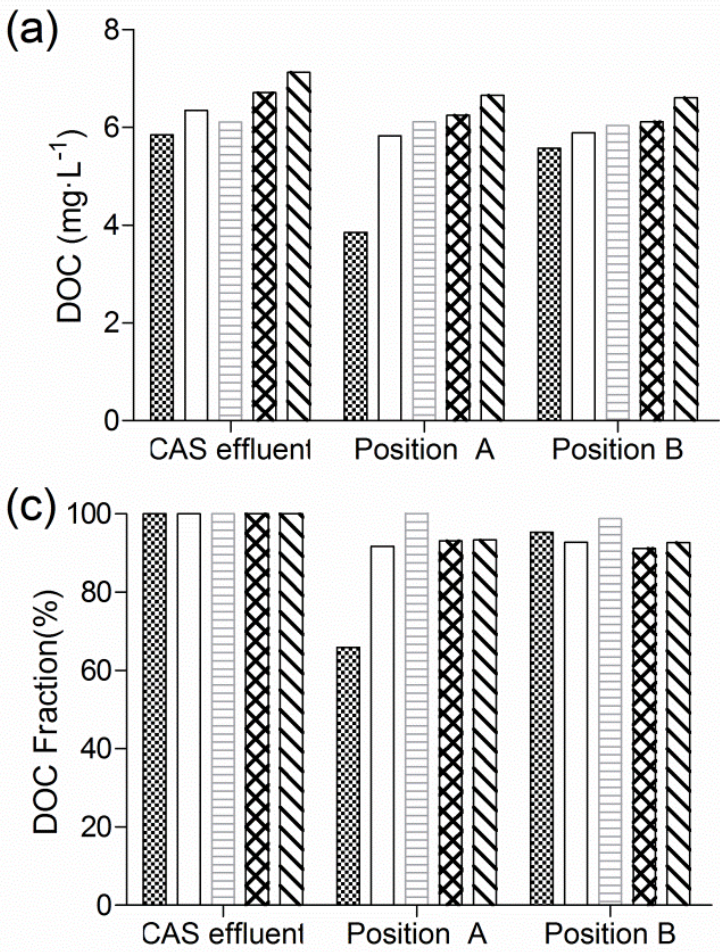
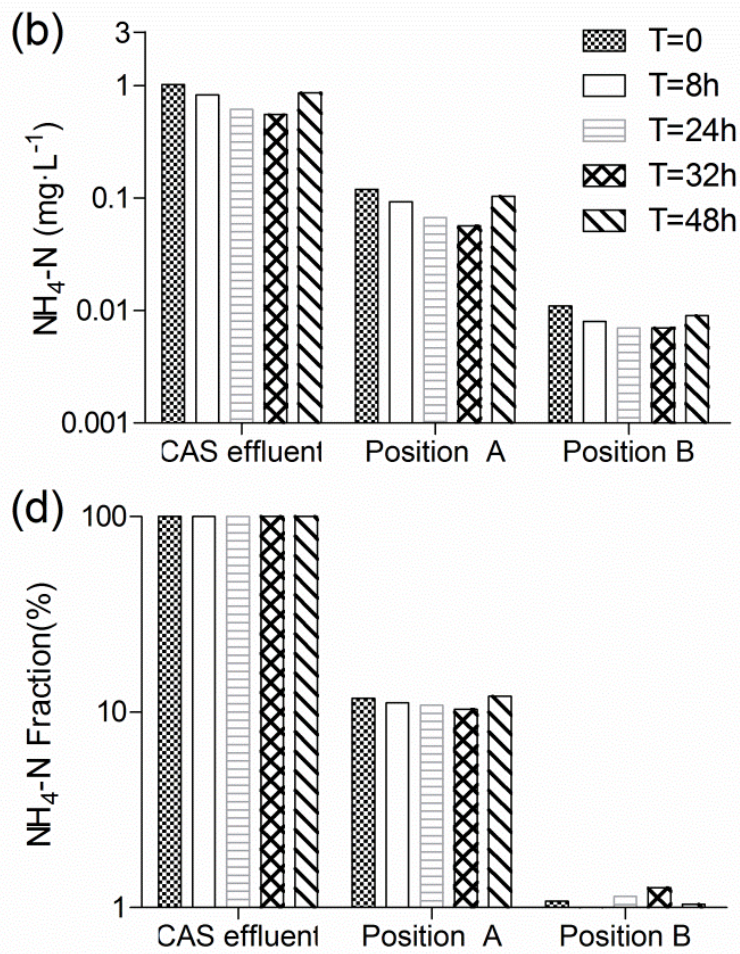

Fig. 3 Influence of interchange feeding to a two-stage MBBR treatment train. (a, b): Concentrations of $\mathrm{NH}_{4}{ }^{+}-\mathrm{N}_{\text {and }} \mathrm{DOC}$ over the time between interchanges of reactor configuration in the two-stage MBBR treatment train during the experimental period for removal of micropollutants. (c, d): fractions of DOC and $\mathrm{NH}_{4}{ }^{+}-\mathrm{N}$ normalised by concentrations of CAS effluent at the same sampling time. 


\subsection{Potential for biodegradation of pharmaceuticals in the MBBRs}

\subsubsection{Biodegradation of pharmaceuticals in batch experiments}

The concentrations for all compounds measured in the batch experiments were plotted over time, and selected pharmaceuticals (acetyl-sulfadiazine, atenolol, diclofenac, sulfadiazine, trimethoprim and venlafaxine) are presented in Fig. 4 while results for all pharmaceuticals can be found in supplementary information (Fig. S3). All compounds were degraded to some extent, except for carbamazepine, which is known to be recalcitrant to biodegradation (Joss et al., 2006). Diclofenac is also rapidly removed in this experiment (Fig. 4) even though it has been repeatedly described as recalcitrant or difficult to biodegrade and it is removed completely within $12 \mathrm{~h}$.

Acetyl-sulfadiazine is a conjugation product formed through the human metabolism of sulfadiazine; however, microorganisms usually de-conjugate this compound rapidly to sulfadiazine again. Similar reactions are known for other sulfonamides (Escolà Casas et al., 2015a, 2015b; Kovalova et al., 2012a). Thus, in this study first an increase in concentration of sulfadiazine was observed as acetyl-sulfadiazine was de-conjugated to form sulfadiazine. Successively the concentrations of sulfadiazine decreased when the conjugate was depleted and the degradation of sulfadiazine itself stated to dominate (Fig. 4). Lubomira et al. (2012b) also found negative biodegradation of sulfadiazine in hospital wastewater treatment by membrane bioreactor.

Relative low removal $(<50 \%)$ for venlafaxine was observed in Fig. 4 after $24 \mathrm{~h}$, which was also found by Falås et al. (2013). The low removal of venlafaxine is of importance, as this compound was found to be the most ozone-resistant pharmaceutical in MBBR-treated hospital wastewater, requiring $1.4 \pm 0.2 \mathrm{mg} \mathrm{O}_{3}$ per DOC to achieve 90\% removal (Hansen et al., 2016).

A first-order kinetic (Eq. 1) was fitted to the concentration curves, and the rate constants (k) of pharmaceuticals for each reactor are shown in Table 2. In general, the first-order kinetic fitted very well $\left(\mathrm{R}^{2}>\right.$ 0.96), except for propranolol, tramadol and venlafaxine (Table S5, SI), as experienced in a previous study (Escolà Casas et al., 2015b). For 12 out of 15 compounds, k in position B was significantly higher compared to position A (Table 2).

In order to investigate the degradation efficiency of pharmaceutical per unit biomass, $\mathrm{k}_{\mathrm{bio}}\left(\mathrm{L} \cdot \mathrm{h}^{-1} \cdot \mathrm{g}^{-1}\right)$ was determined by normalising the rate constants to the biomass of the biofilm on the carriers. Comparing the removal capacity of the reactors in positions $\mathrm{A}$ and $\mathrm{B}, \mathrm{k}_{\mathrm{bio}}$ in position $\mathrm{B}$ was highest for seven compounds, whereas the reactor in position $\mathrm{A}$ had the highest $\mathrm{k}_{\mathrm{bio}}$ for five compounds. For the remaining three compounds, the $\mathrm{k}_{\mathrm{bio}}$ was the same in both positions.
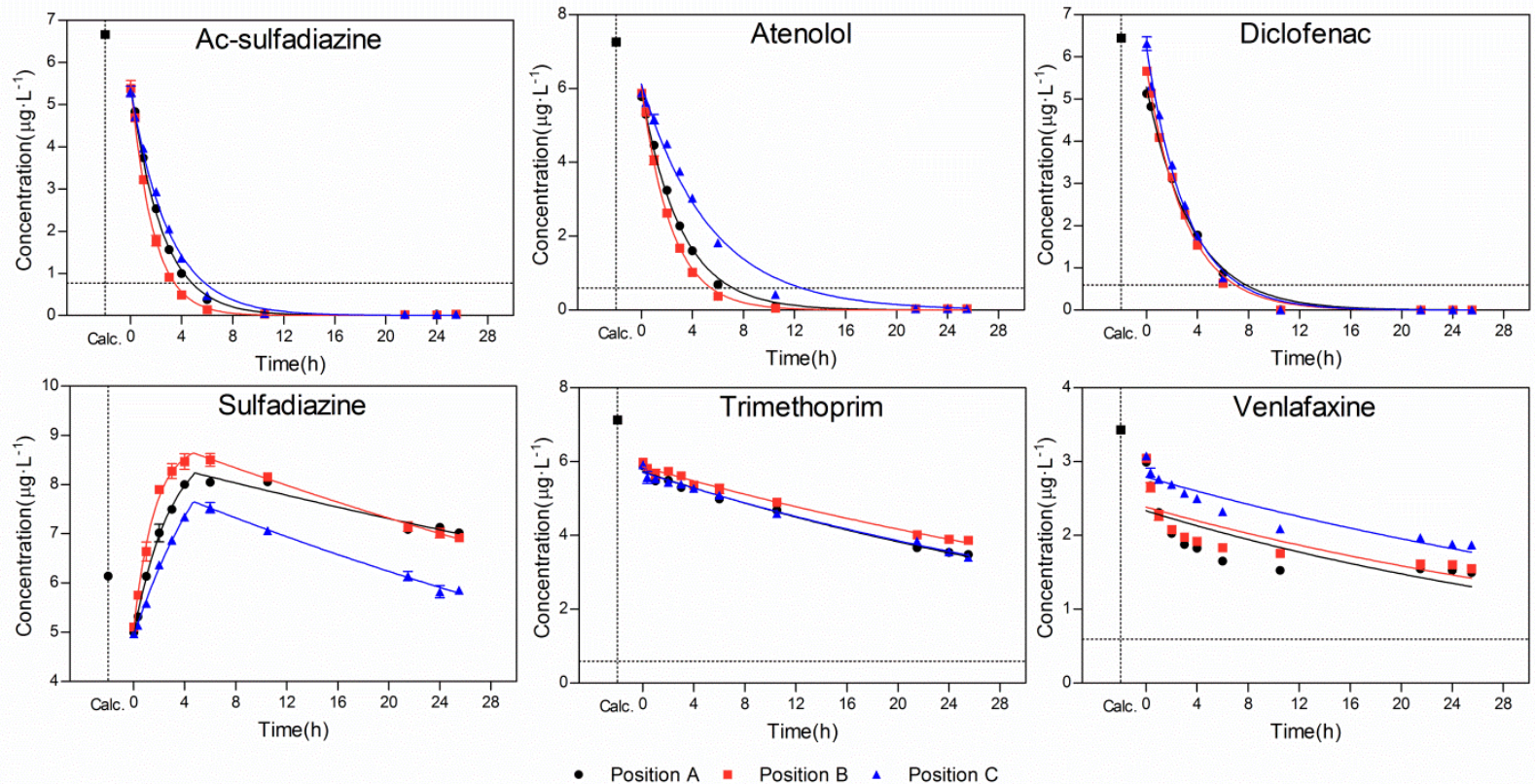

Fig. 4. First-order reaction rate fitting to concentrations of selected pharmaceuticals (except sulfadiazine) in batch experiments (reactor in position A, fed by CAS effluent, and then effluent from position A flows into the reactor in position B. However, the reactor in position $C$ is fed by settled raw wastewater. Before starting the spiking experiment, the flow of each reactor was stopped). The lines satisfy single first order reaction kinetics. The dashed horizontal line stands for the limit of quantification (LOQ). 
Table 2. Comparison of rate constants $\left(k, h^{-1}\right)$ and biomass normalised rate constants $\left(k_{b i o}, L^{\cdot} \cdot h^{-1} \cdot g^{-1}\right)$

\begin{tabular}{|c|c|c|c|c|c|c|c|c|c|c|c|}
\hline \multirow[b]{3}{*}{ Compound } & \multicolumn{3}{|c|}{$\mathrm{k}\left(\mathrm{h}^{-1}\right)$} & \multicolumn{8}{|c|}{$\mathrm{k}_{\text {bio }}\left(\mathrm{L} \cdot \mathrm{h}^{-1} \cdot \mathrm{g}^{-1}\right)$} \\
\hline & \multicolumn{3}{|c|}{ This experiment } & \multicolumn{3}{|c|}{ Effluent polishing of suspended biofilm ${ }^{\text {(This experiment) }}$} & \multicolumn{3}{|c|}{ Staged MBBR WWTP ${ }^{(a)}$} & \multirow{2}{*}{$\begin{array}{c}\text { Effluent polishing } \\
\text { MBBR }^{(\mathrm{b})}\end{array}$} & \multirow{2}{*}{$\begin{array}{l}\text { Biofilm in IFAS } \\
\text { WWTP }^{(\mathrm{c})}\end{array}$} \\
\hline & Position A & Position B & Position C & Position A & Position B & Position C & Stage 1 & Stage 2 & Stage 3 & & \\
\hline Ac-Sulfadiazine & $41 \pm 1 \cdot 10^{-2}$ & $57 \pm 1 \cdot 10^{-2}$ & $33 \pm 1 \cdot 10^{-2}$ & $34 \cdot 10^{-2}$ & $39 \cdot 10^{-2}$ & $24 \cdot 10^{-2}$ & $35 \cdot 10^{-2}$ & $77 \cdot 10^{-2}$ & $3.8 \cdot 10^{-2}$ & $1.1 \cdot 10^{-2}$ & \\
\hline Atenolol & $32 \pm 1 \cdot 10^{-2}$ & $43 \pm 1 \cdot 10^{-2}$ & $19 \pm 1 \cdot 10^{-2}$ & $26 \cdot 10^{-2}$ & $29 \cdot 10^{-2}$ & $13 \cdot 10^{-2}$ & $8.2 \cdot 10^{-2}$ & $18 \cdot 10^{-2}$ & $14 \cdot 10^{-2}$ & $5.0 \cdot 10^{-2}$ & $2.5 \cdot 10^{-2}$ \\
\hline Ciprofloxacin & $79 \pm 17 \cdot 10^{-2}$ & $119 \pm 19 \cdot 10^{-2}$ & $201 \pm 22 \cdot 10^{-2}$ & $65 \cdot 10^{-2}$ & $80 \cdot 10^{-2}$ & $146 \cdot 10^{-2}$ & $0.3 \cdot 10^{-2}$ & $0.8 \cdot 10^{-2}$ & $2.1 \cdot 10^{-2}$ & & \\
\hline Diclofenac & $28 \pm 1 \cdot 10^{-2}$ & $33 \pm 1 \cdot 10^{-2}$ & $32 \pm 1 \cdot 10^{-2}$ & $23 \cdot 10^{-2}$ & $22 \cdot 10^{-2}$ & $23 \cdot 10^{-2}$ & $2.6 \cdot 10^{-2}$ & $5.7 \cdot 10^{-2}$ & $1.5 \cdot 10^{-2}$ & $0.3 \cdot 10^{-2}$ & $6.3 \cdot 10^{-2}$ \\
\hline Ibuprofen & $313 \pm 13 \cdot 10^{-2}$ & $433 \pm 6 \cdot 10^{-2}$ & $181 \pm 7 \cdot 10^{-2}$ & $258 \cdot 10^{-2}$ & $291 \cdot 10^{-2}$ & $131 \cdot 10^{-2}$ & $131 \cdot 10^{-2}$ & $291 \cdot 10^{-2}$ & $48 \cdot 10^{-2}$ & & \\
\hline Iopromide & $0.7 \pm 0.1 \cdot 10^{-2}$ & $3.1 \pm 0.2 \cdot 10^{-2}$ & $1.9 \pm 0.1 \cdot 10^{-2}$ & $0.6 \cdot 10^{-2}$ & $2.1 \cdot 10^{-2}$ & $1.4 \cdot 10^{-2}$ & $0.3 \cdot 10^{-2}$ & $0.7 \cdot 10^{-2}$ & $2.0 \cdot 10^{-2}$ & $0.7 \cdot 10^{-2}$ & \\
\hline Metoprolol & $25 \pm 1 \cdot 10^{-2}$ & $28 \pm 1 \cdot 10^{-2}$ & $12 \pm 1 \cdot 10^{-2}$ & $21 \cdot 10^{-2}$ & $19 \cdot 10^{-2}$ & $8.7 \cdot 10^{-2}$ & $2.3 \cdot 10^{-2}$ & $5.2 \cdot 10^{-2}$ & $3.0 \cdot 10^{-2}$ & $1.0 \cdot 10^{-2}$ & $1.1 \cdot 10^{-2}$ \\
\hline Phenanzone & $1.1 \pm 0.1 \cdot 10^{-2}$ & $1.0 \pm 0.1 \cdot 10^{-2}$ & $1.5 \pm 0.1 \cdot 10^{-2}$ & $0.9 \cdot 10^{-2}$ & $0.7 \cdot 10^{-2}$ & $1.1 \cdot 10^{-2}$ & $0.9 \cdot 10^{-2}$ & $1.9 \cdot 10^{-2}$ & $3.6 \cdot 10^{-2}$ & $0.6 \cdot 10^{-2}$ & $0.4 \cdot 10^{-2}$ \\
\hline Propranolol & $77 \pm 24 \cdot 10^{-2}$ & $77 \pm 26 \cdot 10^{-2}$ & $22 \pm 6 \cdot 10^{-2}$ & $64 \cdot 10^{-2}$ & $52 \cdot 10^{-2}$ & $16 \cdot 10^{-2}$ & $76 \cdot 10^{-2}$ & $169 \cdot 10^{-2}$ & $13 \cdot 10^{-2}$ & $2.1 \cdot 10^{-2}$ & \\
\hline Sotalol & $2.8 \pm 0.1 \cdot 10^{-2}$ & $4.9 \pm 0.1 \cdot 10^{-2}$ & $1.9 \pm 0.1 \cdot 10^{-2}$ & $2.3 \cdot 10^{-2}$ & $3.3 \cdot 10^{-2}$ & $1.4 \cdot 10^{-2}$ & $2.6 \cdot 10^{-2}$ & $5.8 \cdot 10^{-2}$ & $3.1 \cdot 10^{-2}$ & $1.0 \cdot 10^{-2}$ & \\
\hline Sulfamethizole & $5.3 \pm 0.2 \cdot 10^{-2}$ & $14 \pm 1 \cdot 10^{-2}$ & $8.8 \pm 0.7 \cdot 10^{-2}$ & $4.3 \cdot 10^{-2}$ & $9.2 \cdot 10^{-2}$ & $6.4 \cdot 10^{-2}$ & $1.0 \cdot 10^{-2}$ & $2.1 \cdot 10^{-2}$ & $2.9 \cdot 10^{-2}$ & $0.9 \cdot 10^{-2}$ & \\
\hline Sulfamethoxazole & $1.2 \pm 0.0 \cdot 10^{-2}$ & $1.7 \pm 0.1 \cdot 10^{-2}$ & $2.2 \pm 0.0 \cdot 10^{-2}$ & $1.0 \cdot 10^{-2}$ & $1.1 \cdot 10^{-2}$ & $1.6 \cdot 10^{-2}$ & $0.8 \cdot 10^{-2}$ & $1.8 \cdot 10^{-2}$ & $1.1 \cdot 10^{-2}$ & $0.4 \cdot 10^{-2}$ & \\
\hline Tramadol & $2.0 \pm 1.0 \cdot 10^{-2}$ & $2.2 \pm 0.6 \cdot 10^{-2}$ & $2.0 \pm 0.2 \cdot 10^{-2}$ & $1.6 \cdot 10^{-2}$ & $1.5 \cdot 10^{-2}$ & $1.5 \cdot 10^{-2}$ & $0.4 \cdot 10^{-2}$ & $0.8 \cdot 10^{-2}$ & $0.5 \cdot 10^{-2}$ & $0.6 \cdot 10^{-2}$ & \\
\hline Trimethoprim & $2.0 \pm 0.1 \cdot 10^{-2}$ & $1.7 \pm 0.1 \cdot 10^{-2}$ & $2.0 \pm 0.1 \cdot 10^{-2}$ & $1.7 \cdot 10^{-2}$ & $1.1 \cdot 10^{-2}$ & $1.4 \cdot 10^{-2}$ & $2.8 \cdot 10^{-2}$ & $6.3 \cdot 10^{-2}$ & $2.9 \cdot 10^{-2}$ & $1.1 \cdot 10^{-2}$ & $9.0 \cdot 10^{-2}$ \\
\hline Venlafaxine & $2.3 \pm 0.7 \cdot 10^{-2}$ & $2.0 \pm 0.6 \cdot 10^{-2}$ & $1.8 \pm 0.2 \cdot 10^{-2}$ & $1.9 \cdot 10^{-2}$ & $1.4 \cdot 10^{-2}$ & $1.3 \cdot 10^{-2}$ & $0.4 \cdot 10^{-2}$ & $0.9 \cdot 10^{-2}$ & $1.5 \cdot 10^{-2}$ & $0.6 \cdot 10^{-2}$ & $0.4 \cdot 10^{-2}$ \\
\hline
\end{tabular}

(a): a three-stage MBBR system (reactors 1, 2 and 3) fed by wastewater from the oncology section of Aarhus University Hospital (Escolà Casas et al., 2015a).

(b): one-stage MBBR (reactor H4) which was a polishing process after treatment with activated sludge combined with MBBR (Hybas) (also fed by wastewater from the oncology section of Århus University Hospital) (Escolà Casas et al., 2015b).

(c): One-stage IFAS (integrated fixed-film activated sludge, reactor M) stands for a $10 \mathrm{~L}$ reactor filled with wastewater and carriers from a domestic WWTP in Switzerland (Falås et al., 2013). 


\subsubsection{Comparison of rate constants normalized by biomass with other biofilm systems}

Among the researches based on pharmaceuticals degradations by MBBRs, three other studies have investigated the removal of pharmaceuticals in different MBBR systems (Escolà Casas et al., 2015a, 2015b; Falås et al., 2013). Escolà Casas et al. ( 2015a) studied the removal of pharmaceuticals in a staged MBBR in which three MBBR reactors (reactors 1,2 and 3) were placed in a static and unchanged row to treat wastewater from the oncology section of Aarhus University Hospital. In the second study, by Escolà Casas et al. (2015b), the authors investigated the ability of a hybrid MBBR together with suspended biomass $\left(\right.$ Hybas $^{\mathrm{TM}}$ ) to remove pharmaceuticals in wastewater from the same oncology section. This treatment system consisted of four reactors in a static and unchanged row, the first one containing activated sludge, and the second and third reactors containing both activated sludge and biofilm carriers (Hybas), after which the sludge was removed in a settler and returned to reactor 1 . The last reactor (H4) was pure MBBR and acted as a polishing MBBR. In the last study, Falås et al. (2013) carried out batch experiments with carriers taken from a full-scale WWTP (Bad Ragaz WWTP in Switzerland) consisting of anoxic sludge zone, oxic sludge zone and oxic carrier/sludge zone. In all of the studies mentioned above, pharmaceutical degradation was investigated in batch experiments, and the rate constants of the compounds were calculated according to first-order degradation kinetics. Furthermore, the biomass was measured with methods similar to those used in this study. Thus, the obtained biomass normalised rate constants $\left(\mathrm{k}_{\mathrm{bio}}\right)$ can be compared between the different studies (Table 2, Fig. S5).

The same reactors were used in both experiments, the static staged MBBR (Escola Casas et al., 2015a) and the intermittent staged MBBR (this paper) with the only change in feeding the biofilm. We found that the $\mathrm{k}_{\mathrm{bio}}$ of intermittent fed reactors eight out of 15 pharmaceuticals (i.e. atenolol, ciprofloxacin, diclofenac, iopromide, metoprolol, sulfamethizole, tramadol and venlafaxine) for reactors in positions A and B increased in comparison to the static staged reactors. For the remaining compounds, except ibuprofen, the $\mathrm{k}_{\text {bio }}$ in position $\mathrm{A}$ and stage 1 reactor was similar, while $\mathrm{k}_{\mathrm{bio}}$ in position $\mathrm{B}$ was lower than for stage 2 reactor. Ibuprofen had a higher or similar $\mathrm{k}_{\mathrm{bio}}$ compared to previously published studies.

In this study, the flow of feeding to the MBBR treatment trains changed three times per week, all reactors had for two or three days a week a sufficient carbon source available to support biomass growth, as they were fed with settled raw wastewater (position C). This wastewater contained higher amounts of easily biodegradable carbon than CAS effluent water, and it was assumed that this stimulated higher production of enzymes in the biofilm, thereby increasing the capacity to degrade pharmaceuticals.

Ibuprofen and diclofenac are both non-steroidal anti-inflammatory drugs, albeit with very different fates in WWTPs (Joss et al., 2005; Vieno and Sillanpää, 2014). Ibuprofen is an easily biodegradable compound, whereas diclofenac is much more difficult to be degraded; in fact, the $\mathrm{k}_{\mathrm{bio}}$ for diclofenac in our study was 10 times lower than that for ibuprofen, while $\mathrm{k}_{\mathrm{bio}}$ of diclofenac in previous studies has even been 100 times lower than $\mathrm{k}_{\mathrm{bio}}$ of ibuprofen in this study.

All beta blockers, i.e., atenolol, metoprolol, propranolol and sotalol have similar chemical structures and properties. For atenolol and metoprolol, Table 2 shows that the $\mathrm{k}_{\mathrm{bio}}$ of both reactors in positions A and B are higher than in previous studies. However, the $\mathrm{k}_{\mathrm{bio}}$ regarding propranolol and sotalol, in the reactors from the statically staged MBBR (Escolà Casas et al., 2015a) were higher than the intermittently fed ones as well as other studies from Table 2 (Escolà Casas et al., 2015b; Falås et al., 2013).

Previous studies have observed that MBBRs have the capacity to degrade several X-ray contrast media (i.e. iohexol and diatrizoic acid) (Escolà Casas et al., 2015a; Hapeshi et al., 2013). For iopromide, Escolà Casas et al. (Escolà Casas et al., 2015a) found that $\mathrm{k}_{\text {bio }}$ increased from the first to the third reactor in the staged MBBR. In our study, $k_{\text {bio }}$ for iopromide also increased in the second reactor (position $B$ ) compared to the first (position $\mathrm{A}$ ), and in general the value of $\mathrm{k}_{\mathrm{bio}}$ was in the same order of magnitude as in previous studies (Table 2).

Similar results can also be found for sulfamethizole (an antibiotic). $\mathrm{k}_{\mathrm{bio}}$ in positions A and B, especially position $\mathrm{B}$, were significantly higher than $\mathrm{k}_{\mathrm{bio}}$ of the three reactors from the statically staged MBBR (Escolà Casas et al., 2015a). This proves further that interchanging the reactors ensures ongoing and sufficient growth and therefore avoids starving the biofilm, as seen in previous experiments. As a result, it could achieve better biodegradation of pharmaceuticals and moreover reduce the retention time required in a polishing MBBR system. 


\subsubsection{Mechanistic considerations}

An important question on degradation of micropollutants with biofilms is whether degradation occurs via codegradation (the more substrate is available, the higher the degradation rate) or the right community composition makes a biofilm degrade.

In Fig. 4 and Fig. S3, the pharmaceuticals removal kinetics is very similar between the three reactors although the abundance of substrate differs massively (CAS effluent versus settled raw wastewater). Due to the rapid exchange of reactor conditions the biomass is more or less identical in the 3 reactors, which is also observed from that the biomass are similar in the three reactors as mentioned in section 3.1.1. Therefor the high similarity in biodegradation kinetic indicates that co-degradation (and thus primary substrate) is less important for biodegradation than the quality of the degraders present in the biofilm.

\subsection{Polishing of pharmaceuticals by a MBBR system in flow-through mode}

\subsubsection{Flow through experiment}

The experiment was carried out with naturally occurring concentrations of pharmaceuticals, with no spiking applied (Fig. 5). The concentrations of the selected compounds in Fig. 5 were above LOQ. As ibuprofen and ciprofloxazin with a high degree removed in the CAS WWTP, these compounds were barely detectable in the influent and completely removed in the reactor in position A.

No negative removal except for sulfamethizole was observed, which suggests that the conjugates and metabolites were mainly converted to parent compounds in the conventional WWTP.

By changing HRT, the interaction time between biofilm of carriers and compounds was directly changed. Furthermore, the removal of pharmaceuticals increased in line with an increase in HRT; for instance, atenolol was totally degraded when HRT increased from $1 \mathrm{~h}$ to $4 \mathrm{~h}$, and the removal of metoprolol increased from $7 \%$ to $69 \%$ while the removal of propranolol increased from $3 \%$ to $43 \%$. For sulfamethizole, removal changed from negative to $48 \%$. 

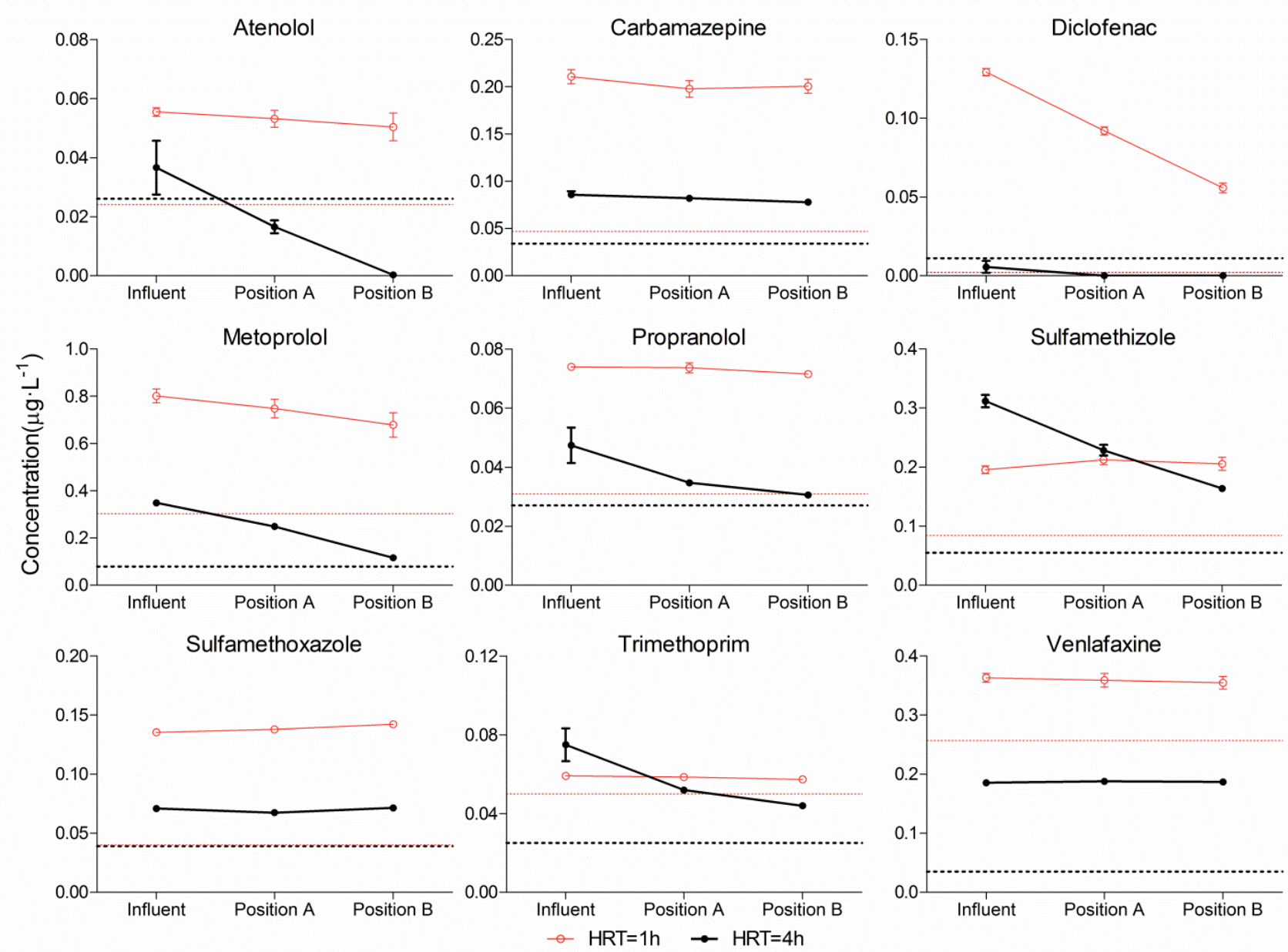

Fig. 5. Concentrations of selected pharmaceuticals in continuous experiments with different HRTs. The dashed horizontal lines indicate the LOQ for each pharmaceutical derived from two multiple reaction monitoring (MRM) transitions. Values below the LOQ are based on a single MRM transition only.

\subsubsection{Predicted and observed removal of pharmaceuticals in MBBRs}

According to equation 3, the predicted removal of pharmaceuticals was calculated based on the obtained rate constant for each pharmaceutical in the batch experiment. A comparison of both predicted and observed removals in flow through experiments with HRT $=1$ and $4 \mathrm{~h}$ respectively, is presented in Fig. 6 . The compound with the lowest predicted removal was iopromide, while ibuprofen had the highest predicted removal.

At $\mathrm{HRT}=1 \mathrm{~h}$, the reactor in position B made almost the same contribution to removing the compounds as the reactor in position A. When increasing the HRT to 4 hours, the main degradation occurred in the reactor in position A for compounds with a high removal rate (> 60\%), while having the reactor in positions $\mathrm{A}$ and $\mathrm{B}$ contributed equally to the removal of the remaining pharmaceuticals.

The observed removals were similar to the predictions made for compounds with a low removal rate $(<20 \%)$ at HRT = 1 hour, while for the majority of the remaining compounds the observed removal was lower than predicted. For diclofenac, the observed removal was much higher than the predicted one for both HRTs. 

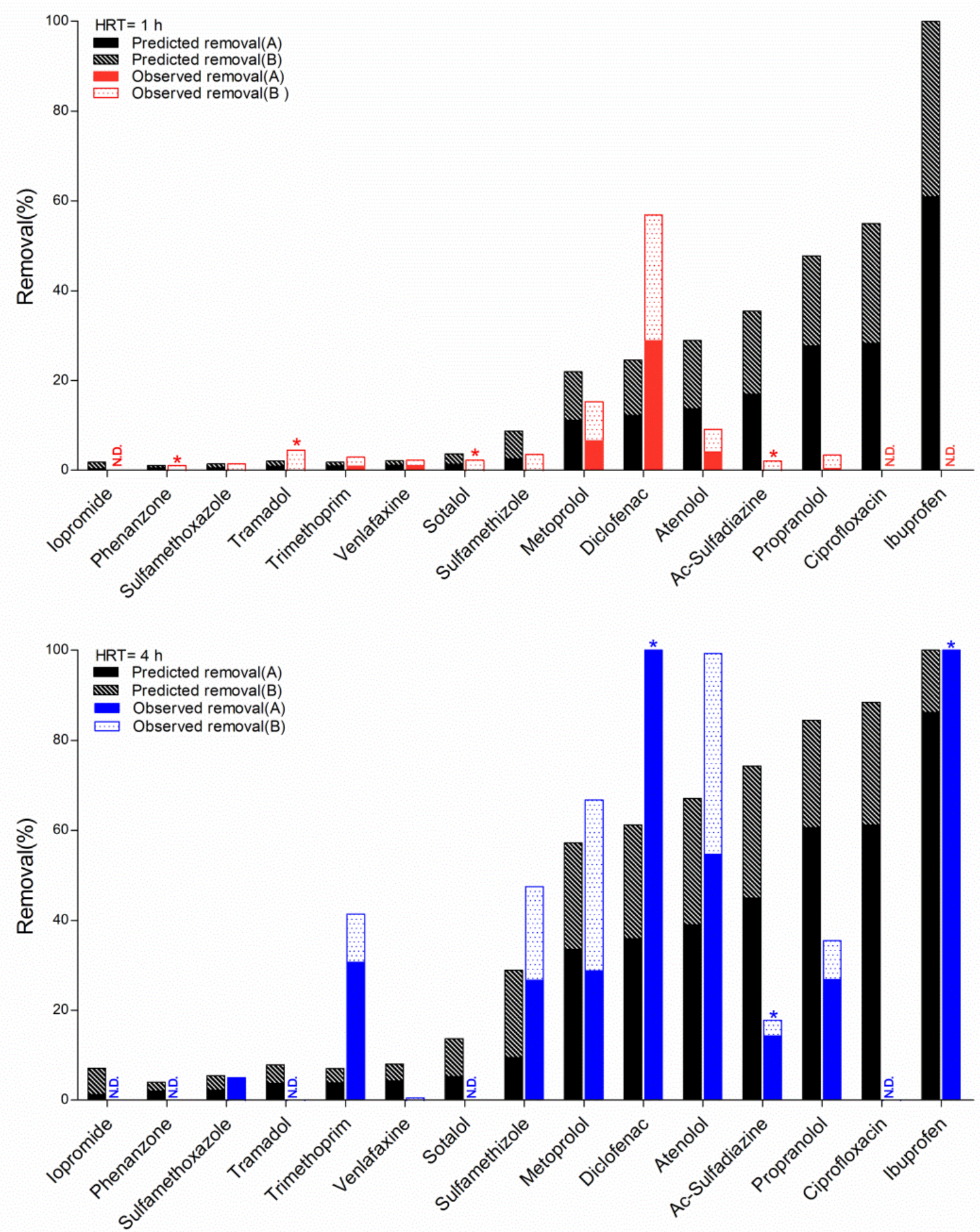

Fig. 6. Comparison of predicted and observed pharmaceutical removal in the MBBR train. (N.D. refers to not detected; a star indicates that compound concentration was below LOQ).

\section{Conclusion}

Biofilms grown on carriers in reactors intermittently fed with BOD rich (settled) wastewater can be used to remove pharmaceuticals from effluent water of a conventional activated sludge wastewater treatment plant and thus to polish its effluent. This biofilm also removes ammonia to a high extent. 
The biofilm in the intermittently fed MBBR demonstrated the capacity to degrade pharmaceuticals that have hitherto been considered as recalcitrant (e.g. diclofenac) as they are not removed by activated sludge in the WWTP.

In this study, it was found that diclofenac and atenolol were removed $>50 \%$ from the WWTP effluent by the polishing biofilm which was grown using intermittent feeding.

\section{Acknowledgments}

The authors acknowledge the funding to the MERMISS project (Miljøeffektiv rensning af højpotente lægemiddelstoffer i hospitalsspildevand/Environmentally effective removal of pharmaceuticals from hospital wastewater) from the MUDP program by the Danish Ministry of the Environment. The authors also appreciate that the described concept is covered by the Swedish patent application 1650321-1.a by Veolia WT.

\section{References}

Biswas, K., Taylor, M.W., Turner, S.J., 2014. Successional development of biofilms in moving bed biofilm reactor (MBBR) systems treating municipal wastewater. Appl. Microbiol. Biotechnol. 98, 1429-1440. doi:10.1007/s00253-013-5082-8

Bottoni, P., Caroli, S., Caracciolo, A.B., 2010. Pharmaceuticals as priority water contaminants. Toxicol. Environ. Chem. 92, 549-565. doi:10.1080/02772241003614320

Chen, S., Sun, D., Chung, J.S., 2008. Simultaneous removal of COD and ammonium from landfill leachate using an anaerobic-aerobic moving-bed biofilm reactor system. Waste Manag. 28, 339-346. doi:10.1016/j.wasman.2007.01.004

Emke, E., Evans, S., Kasprzyk-Hordern, B., de Voogt, P., 2014. Enantiomer profiling of high loads of amphetamine and MDMA in communal sewage: A Dutch perspective. Sci. Total Environ. 487, 666-672. doi:10.1016/j.scitotenv.2013.11.043

Escolà Casas, M., Chhetri, R.K., Ooi, G., Hansen, K.M.S., Litty, K., Christensson, M., Kragelund, C., Andersen, H.R., Bester, K., 2015a. Biodegradation of pharmaceuticals in hospital wastewater by staged Moving Bed Biofilm Reactors (MBBR). Water Res. 83, 293-302. doi:10.1016/j.watres.2015.06.042

Escolà Casas, M., Chhetri, R.K., Ooi, G., Hansen, K.M.S., Litty, K., Christensson, M., Kragelund, C., Andersen, H.R., Bester, K., 2015b. Biodegradation of pharmaceuticals in hospital wastewater by a hybrid biofilm and activated sludge system (Hybas). Sci. Total Environ. 530-531, 383-392. doi:10.1016/j.scitotenv.2015.05.099

Falås, P., Baillon-Dhumez, A., Andersen, H.R., Ledin, A., la Cour Jansen, J., 2012. Suspended biofilm carrier and activated sludge removal of acidic pharmaceuticals. Water Res. 46, 1167-1175. doi:10.1016/j.watres.2011.12.003

Falås, P., Longrée, P., la Cour Jansen, J., Siegrist, H., Hollender, J., Joss, A., 2013. Micropollutant removal by attached and suspended growth in a hybrid biofilm-activated sludge process. Water Res. 47, 44984506. doi:10.1016/j.watres.2013.05.010

Falås, P., Wick, A., Castronovo, S., Habermacher, J., Ternes, T.A., Joss, A., 2016. Tracing the limits of organic micropollutant removal in biological wastewater treatment. Water Res. 95, 240-249. doi:10.1016/j.watres.2016.03.009

Hansen, K.M.S., Spiliotopoulou, A., Chhetri, R.K., Escolà Casas, M., Bester, K., Andersen, H.R., 2016. Ozonation for source treatment of pharmaceuticals in hospital wastewater - Ozone lifetime and required ozone dose. Chem. Eng. J. 290, 507-514. doi:10.1016/j.cej.2016.01.027

Hapeshi, E., Lambrianides, A., Koutsoftas, P., Kastanos, E., Michael, C., Fatta-Kassinos, D., 2013. Investigating the fate of iodinated $\mathrm{X}$-ray contrast media iohexol and diatrizoate during microbial degradation in an MBBR system treating urban wastewater. Environ. Sci. Pollut. Res. 20, 3592-3606. doi:10.1007/s11356-013-1605-1 
Hem, L., Rusten, B., Ødegaard, H., 1994. Nitrification in a moving bed biofilm reactor. Water Res. 28, 14251433. doi:10.1016/0043-1354(94)90310-7

Henze, M., Loosdrecht, M.C. van, Ekama, G.A., Brdjanovic, D., 2008. Biological Wastewater Treatment: Principles, Modelling and Design, 1st ed. IWA Publishing.

Hollender, J., Zimmermann, S.G., Koepke, S., Krauss, M., Mcardell, C.S., Ort, C., Singer, H., Von Gunten, U., Siegrist, H., 2009. Elimination of organic micropollutants in a municipal wastewater treatment plant upgraded with a full-scale post-ozonation followed by sand filtration. Environ. Sci. Technol. 43, 78627869. doi:10.1021/es9014629

Joss, A., Keller, E., Alder, A.C., Göbel, A., McArdell, C.S., Ternes, T., Siegrist, H., 2005. Removal of pharmaceuticals and fragrances in biological wastewater treatment. Water Res. 39, 3139-3152. doi:10.1016/j.watres.2005.05.031

Joss, A., Zabczynski, S., Göbel, A., Hoffmann, B., Löffler, D., McArdell, C.S., Ternes, T.A., Thomsen, A., Siegrist, H., 2006. Biological degradation of pharmaceuticals in municipal wastewater treatment: Proposing a classification scheme. Water Res. 40, 1686-1696. doi:10.1016/j.watres.2006.02.014

Kovalova, L., Siegrist, H., Singer, H., Wittmer, A., McArdell, C.S., 2012a. Hospital wastewater treatment by membrane bioreactor: Performance and efficiency for organic micropollutant elimination. Environ. Sci. Technol. 46, 1536-1545. doi:10.1021/es203495d

Kovalova, L., Siegrist, H., Singer, H., Wittmer, A., McArdell, C.S., 2012b. Hospital wastewater treatment by membrane bioreactor: Performance and efficiency for organic micropollutant elimination. Environ. Sci. Technol. 46, 1536-1545. doi:10.1021/es203495d

Luo, Y., Jiang, Q., Ngo, H.H., Nghiem, L.D., Hai, F.I., Price, W.E., Wang, J., Guo, W., 2015. Evaluation of micropollutant removal and fouling reduction in a hybrid moving bed biofilm reactor-membrane bioreactor system. Bioresour. Technol. 191, 355-359. doi:10.1016/j.biortech.2015.05.073

Mazioti, A.A., Stasinakis, A.S., Psoma, A.K., Thomaidis, N.S., Andersen, H.R., 2016. Hybrid Moving Bed Biofilm Reactor for the biodegradation of benzotriazoles and hydroxy-benzothiazole in wastewater. J. Hazard. Mater. doi:10.1016/j.jhazmat.2016.06.035

Mazioti, A. a., Stasinakis, A.S., Pantazi, Y., Andersen, H.R., 2015. Biodegradation of benzotriazoles and hydroxy-benzothiazole in wastewater by activated sludge and moving bed biofilm reactor systems. Bioresour. Technol. 192, 627-635. doi:10.1016/j.biortech.2015.06.035

Muñoz, I., Martínez Bueno, M.J., Agüera, A., Fernández-Alba, A.R., 2010. Environmental and human health risk assessment of organic micro-pollutants occurring in a Spanish marine fish farm. Environ. Pollut. 158, 1809-1816. doi:10.1016/j.envpol.2009.11.006

Oliveira, D.V.M. De, 2014. Evaluation of a MBBR (Moving Bed Biofilm Reactor) Pilot Plant for Treatment of Pulp and Paper Mill Wastewater. Int. J. Environ. Monit. Anal. 2, 220. doi:10.11648/j.ijema.20140204.15

Rivera-Utrilla, J., Prados-Joya, G., Sánchez-Polo, M., Ferro-García, M. a., Bautista-Toledo, I., 2009. Removal of nitroimidazole antibiotics from aqueous solution by adsorption/bioadsorption on activated carbon. J. Hazard. Mater. 170, 298-305. doi:10.1016/j.jhazmat.2009.04.096

Santos, J.L., Aparicio, I., Callejón, M., Alonso, E., 2009. Occurrence of pharmaceutically active compounds during 1-year period in wastewaters from four wastewater treatment plants in Seville (Spain). J. Hazard. Mater. 164, 1509-1516. doi:10.1016/j.jhazmat.2008.09.073

Simazaki, D., Fujiwara, J., Manabe, S., Matsuda, M., Asami, M., Kunikane, S., 2008. Removal of selected pharmaceuticals by chlorination, coagulation- sedimentation and powdered activated carbon treatment. Water Sci. Technol. 58, 1129-1135. doi:10.2166/wst.2008.472

Tang, K., Escola Casas, M., Ooi, G.T.H., Kaarsholm, K.M.S., Bester, K., Andersen, H.R., 2017. Influence of humic acid addition on the degradation of pharmaceuticals by biofilms in effluent wastewater. Int. J. 
Hyg. Environ. Health 1-7. doi:10.1016/j.ijheh.2017.01.003

Verlicchi, P., Al Aukidy, M., Galletti, a., Zambello, E., Zanni, G., Masotti, L., 2012a. A project of reuse of reclaimed wastewater in the Po Valley, Italy: Polishing sequence and cost benefit analysis. J. Hydrol. 432-433, 127-136. doi:10.1016/j.jhydrol.2012.02.024

Verlicchi, P., Al Aukidy, M., Zambello, E., 2012b. Occurrence of pharmaceutical compounds in urban wastewater: Removal, mass load and environmental risk after a secondary treatment-A review. Sci. Total Environ. 429, 123-155. doi:10.1016/j.scitotenv.2012.04.028

Vieno, N., Sillanpää, M., 2014. Fate of diclofenac in municipal wastewater treatment plant - A review. Environ. Int. 69, 28-39. doi:10.1016/j.envint.2014.03.021

Zuccato, E., Castiglioni, S., Bagnati, R., Melis, M., Fanelli, R., 2010. Source, occurrence and fate of antibiotics in the Italian aquatic environment. J. Hazard. Mater. 179, 1042-1048. doi:10.1016/j.jhazmat.2010.03.110

Zupanc, M., Kosjek, T., Petkovšek, M., Dular, M., Kompare, B., Širok, B., Blažeka, Ž., Heath, E., 2013. Removal of pharmaceuticals from wastewater by biological processes, hydrodynamic cavitation and UV treatment. Ultrason. Sonochem. 20, 1104-1112. doi:10.1016/j.ultsonch.2012.12.003 